\title{
Research on vertical welding process of arc welding robot
}

\author{
Zhang Wenming, Dong Zhihai
}

( School of Mechanical Engineering, Shenyang University, Shenyang 110044, China)

Key words:robot; vertical; welding;welding parameters

\begin{abstract}
The problem of weld formation in vertical welding is the difficulty of automatic welding technology of welding robot, which is easy to produce welding deformation, the welding seam is not fused, and the height is too high. In the welding process, to take effective measures to effectively solve the welding defects, weld forming and welding quality problems. In addition, the correct use of welding fixture also plays an important role in the welding deformation. Opposition of repeated tests to the weld, the welding parameters and welding torch position adjusting constantly, obtain a set of suitable welding process parameters to weld the end, for enterprises to use the automatic welding robot to provide reference and help.
\end{abstract}

\section{1 .Introduction}

Welding is a very important work in industry. In the past, most of them adopt manual upward welding, but there are many disadvantages such as low production efficiency, slow welding speed, high welding cost and high welding strength. Therefore, the new type of automatic welding will become the inevitable trend of future technology development. In this paper, the problem of vertical welding process of arc welding robot is introduced. Through the study of thin vertical down welding welding process to simulate thin-walled pipe welding, using special fixture greatly reduces the problem of sheet metal welding deformation in the welding process, through repeated experiments finally draw a suitable set of vertical welding parameters to welding, welding automation for the enterprise is a vertical pipe connected with the welding reference.

\section{2 .Welding of sheet}

The test specimens were selected by Q235B cold rolled steel plate with thickness of $1.5 \mathrm{~mm}$. Q235B steel plate is more representative in industrial application, and can be used to simulate the vertical longitudinal seam welding of thin-walled pipe. The chemical composition of the material and self inspection results are shown in Table 1. 
Table 1 chemical composition of Q235B steel

\begin{tabular}{llllll}
\hline project $(\%)$ & $\omega(\mathrm{C})$ & $\omega(\mathrm{Mn})$ & $\omega(\mathrm{Si})$ & $\omega(P)$ & $\omega(S)$ \\
\hline GB/T700-2006 & $0.12 \sim 0.20$ & $0.30 \sim 0.670$ & $\leq 0.30$ & $\leq 0.045$ & $\leq 0.045$ \\
Certificate & 0.14 & 0.30 & 0.30 & 0.020 & 0.010 \\
The reinspection & 0.14 & 0.30 & 0.020 & 0.010 \\
\hline & Cep $=C+\frac{M n}{6}+\frac{C r+M o+V}{5}+\frac{N i+C u}{15}=0.14+\frac{0.3}{6}=0.19 \%$
\end{tabular}

It is found that the carbon equivalent is $0.19 \%$, because when the carbon equivalent is $0.12 \% \sim 0.2 \%$, the welding performance is the best, and the weld and heat affected zone are easy to be brittle when the carbon content exceeds the above range. Generally, the carbon content of Q235A is higher, and the carbon content is not used as the delivery condition, so this grade is usually not used for welding components. The carbon content of Q235B is controlled in the range of the above mentioned, so the welding performance of Q235B steel is good, the cold crack tendency is not big, and it does not need preheating under the specific condition. Therefore suitable for welding. However, due to the deformation and burn through in the welding process, the heat input should be controlled.

\section{3 .preparation before welding}

This experiment chooses the Universal Robots UR5 proud (optimal robot. 5), the $\mathrm{CO}+\mathrm{Ar}$ mix gas shielded welding. Welding machine chooses panasonic YD - 350 gs, this welding machine adopts unique initial control method of short circuit and neck detection control method, make the splash generates greatly reduced. Visibility and operability is strong, stable performance, flexibility, robustness, dustproof performance improvement. Small heat input, through the compression arc width and length, suppresses the high-speed welding bite edge. The nominal welding current is $500 \mathrm{~A}$, rated load duration rate is $60 \%$, adopts dc reverse method, when the welding sheet welding wire with A diameter of $1.0 \mathrm{~mm}$ H08Mn2SiA. Chosen before welding robot welding torch and the weld position, observe whether there is a collision with the fixture of robot joints. Such as have occurred in a timely manner to adjust the welding position.

\section{4. welding process and experiment}

\section{1 welding methods}

$\mathrm{CO}+\mathrm{Ar}$ mixed gas MIG welding. Before welding the first two steel plate in the back of the point of solid welding, one is to facilitate the fixation of the specimen to obtain a seamless vertical weld, the two is an effective way to prevent the deformation of the welding process. The specimen with good fixation can be used to avoid the welding 
deformation during welding.

\section{2 welding groove}

The I type groove is adopted for the welding specimen, and the gap free form.

\section{3 welding procedure specification}

In the course of the experiment, the welding position, welding torch swing and welding speed have great influence on the welding parameters. Therefore, the welding robot welding gun position before welding. Adjust the angle of the welding torch to the level of 120 degrees, and the vertical angle of about 80 degrees. The section shows the distance between the welding wire and the welding seam is about $1 \mathrm{~mm}$. Everything is ready to start the experiment. As shown in figure 1.

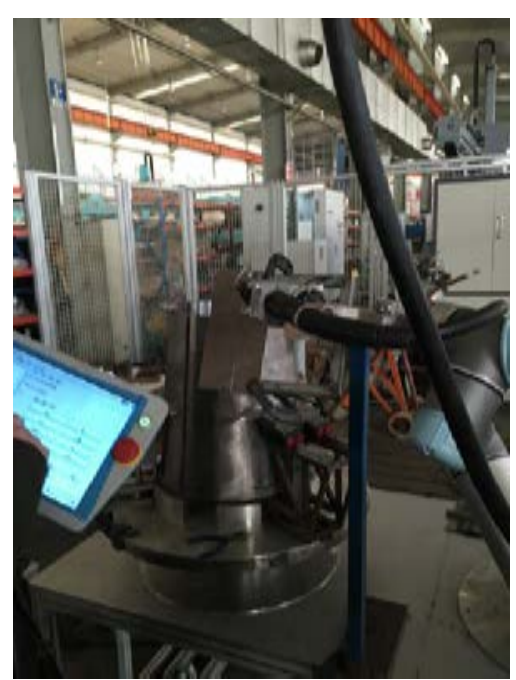

Fig. 1 fixture and robot welding gun position

\section{5 .experimental results and analysis}

In the early stage of experiment, the matching of current, voltage and welding speed can not be satisfied. After welding, it is found that the weld is generally formed in the front, and it is easy to produce welding thermal deformation in the middle of the welding. Weld is easy to produce the edge is not fused, the higher the situation. Through the experiment, changing the current, voltage and welding speed in the non quantitative to find the ideal forming effect, get a set of appropriate welding parameters. Table 2 welding parameters during the experiment. Welding results are shown in figure 2. 
Table 2 welding parameters and forming conditions

\begin{tabular}{ccccccc}
\hline 组数 & 示教盒 $\mathrm{I} / \mathrm{A}$ & 示教盒 $\mathrm{U} / \mathrm{V}$ & 电流 $\mathrm{I} / \mathrm{A}$ & 电压 $\mathrm{U} / \mathrm{V}$ & 焊接速度 $v / \mathrm{mm} \cdot \mathrm{s}_{-1}$ & 缺陷及成型 \\
\hline 1 & 2.6 & 6.35 & 82 & 15.3 & 7.5 & 未熔合, 成形差 \\
2 & 2.6 & 6.30 & 85 & 15.9 & 7.5 & 前期良好, 变形后成形差 \\
3 & 2.8 & 6.8 & 90 & 16.9 & 5 & 未熔合, 余高大, 成形一般 \\
4 & 3.0 & 6.8 & 96 & 16.9 & 5 & 成形良好 \\
5 & 3.1 & 6.8 & 99 & 17.1 & 5 & 7 \\
6 & 3.1 & 6.8 & 99 & 17.0 & 6 & 边缘未熔合, 成形一般 \\
7 & 3.3 & 6.0 & 105 & 15.8 & 6 & 余高大, 变形大, 成形差 \\
8 & 3.3 & 6.8 & 105 & 16.9 & 6 & 成形良好 \\
& & & & & & 成形最好 \\
\hline
\end{tabular}
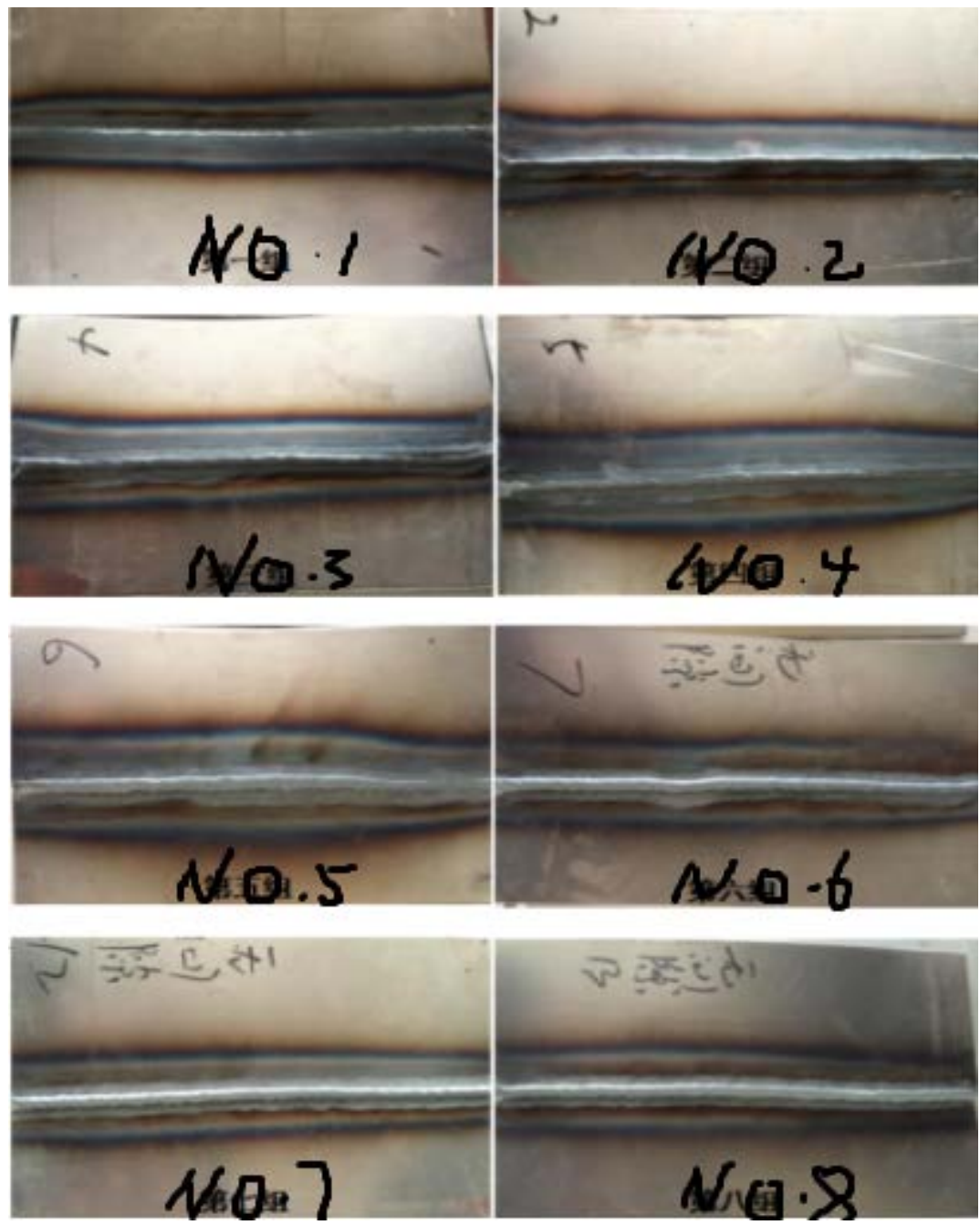

Figure 2 welding results 


\section{Conclusion}

The experimental results show that the welding robot can obtain stable welding quality and good surface forming by welding the welding parameters and the welding details. As for the different thickness of the plate, weld specifications, welding materials, as long as some of the parameters change, other parameters should also follow the change to the corresponding value. Finally, the ideal welding result is obtained.

\section{Reference:}

[1] Zong Li, He Jianping, Wang Fuxin. Research on the special problems of sheet metal welding [J]. welding technology, 2015, 2(44) :1-4.

[2] Zongtao, Sun Bo, Li Chunrun, et al. Research progress on welding deformation of thin plate welding [J]. modern control measures, 2011 (7): 20-21.

[3] Song Jian, Wang Jianli, Wang Feng. Deformation analysis of thin plate welding [J]. hot working technology, 2013, 42 (15): 164-165.

[4] Welding Engineering Society of China Mechanical Engineering Society. Welding manual (volume third) [M]. Beijing: China Machine Press, 2007

[5] Zhang Zhengbing, Li Xiaona. Application of robot in welding. Welding machine, 20086 (38): 44-46. 
